\title{
Uma breve caminhada pela tradução literária: mediando palavras e culturas
}

Resumo: Este artigo visa analisar, embora de forma reduzida, os aspectos socioculturais de uma tradução literária, assim como oferecer uma breve abordagem dos métodos e dos desafios da tradução de textos literários, tendo como base teórica os conceitos e métodos de tradução tais como: Bassnett (2002), Derrida (2001), Furlan (1998), Gentzler (1990), Lefevere (2003), Munday (2001), Nida (1991), Oittinen (2002), Ricouer (2006) e Venuti (2004). Um estudo conciso também se dará do tema tradução e as implicações linguístico-culturais enfrentadas pelo tradutor literário. Serão analisados aspectos do texto original que "se perdem" numa adaptação ou tradução dando uma ênfase especial aos conceitos de domesticação e estrangeirização para melhor atender às necessidades do leitor final. Igualmente, o artigo examina como o tradutor literário funciona como uma espécie de guardião de segredos que leva e traz informação na procura incessante de significado entre o texto de partida (TP) e cultura de partida (CP) e o texto de chegada (TC) e cultura de chegada (CC), e como a tradução funciona como mediadora sociocultural.

Palavras-Chave: Tradução Literária. Mediadora Sociocultural. Teorias Tradutológicas.

\section{A brief stroll through literary translation: mediating words and cultures}

\begin{abstract}
This article seeks to briefly analyze the sociocultural aspects of a literary translation, as well as to offer a condensed overview of the methods and challenges faced in the translation of literary texts, based on the translation concepts and methods of theorists such as: Bassnett (2002), Derrida (2001), Furlan (1998), Gentzler (1990), Lefevere (2003), Munday (2001), Nida (1991), Oittinen (2002), Ricouer (2006) e Venuti (2004). We also offer a concise study of translation and the cultural-linguistic implications faced by the literary translator. Aspects of the original texts that "get lost" in an adaptation or translation will be analyzed, giving special emphasis to the concepts of domestication and foreignization to better meet the needs of the end reader. Likewise, the article examines how the literary translator acts as a type of guardian of secrets that relays information back and forth in an incessant search for meaning between the source text (ST) and source culture (SC) and the target text (TT) and culture (TC), and the role of translation as a sociocultural mediator.
\end{abstract}

Keywords: Literary Translation. Sociocultural Mediator. Translation Theories.

\section{Introdução}

A tradução literária como mediadora sociocultural tem o poder de ultrapassar tempos, culturas e histórias para trazer novas experiências, perspectivas e prazeres para uma multiplicidade de leitores em culturas e países diferentes. O tradutor literário, por sua

\footnotetext{
${ }^{1}$ Doutora em Línguas Neolatinas pela Universidade da Geórgia, EUA (PhD - Romance Languages), Mestra em Letras - Literatura e Crítica Literária pela PUC Goiás, e Graduada em Letras - Espanhol e Inglês pela Georgia State University, EUA. Professora Assistente I no Departamento de Letras e Professora Colaboradora no Programa de Pós-Graduação em Letras da PUC Goiás, 62-8161-6296, toniawind@gmail.com.
} 
vez, se encontra numa verdadeira encruzilhada na qual ele se apresenta com um pé no texto original e seu rico contexto sociocultural e o outro no contexto sociocultural do país para o qual fará a adaptação ou tradução do texto original. Ao pensar na influência da tradução de livros no processo cultural de um povo, levantamos aqui as implicações linguístico-culturais enfrentadas pelo tradutor literário ao passar pelo processo tradutológico. Usamos a ideia de mosaico de cultura para adentrarmos no assunto de qual a influência da leitura e dos livros estrangeiros dentro da composição cultural de um país, assim como para referirmos a todos os grupos distintas que compõem o mosaico sociocultural.

É dentro desta perspectiva de fragmentos de culturas diferentes que se intercalam para formar mosaicos de gente, de crenças, de visões do mundo e o papel da tradução literária como mediadora de palavras e culturas que pretendemos fazer uma breve caminhada pela tradução literária. Sendo assim, nosso estudo visa analisar os aspectos socioculturais de uma tradução literária, e oferecer uma breve abordagem dos métodos e dos desafios da tradução de textos literários, tendo como base teórica os conceitos e métodos de tradução tais como: BASSNETT (2002), DERRIDA (2001), FURLAN (1998), GENTZLER (1990), LEFEVERE (2003), MUNDAY (2001), NIDA (1991), OITTINEN (2002), RICOUER (2006) e VENUTI (2004).

\section{Aspectos Socioculturais da Literatura}

O ser humano se vê fortemente influenciado por todos os sistemas culturais da sua sociedade. Ou, nas palavras de Stuart Hall, "No mundo moderno, as culturas nacionais em que nascemos se constituem em uma das principais fontes de identidade cultural" (HALL: 2006, 47). Ao nos focarmos no conceito de cultura dentro do mundo literário, podemos pensar, junto a Peter Hunt, que ela é um conjunto de histórias que contamos uns aos outros sobre nós mesmos (HUNT: 1999, 36) e, seguindo o pensamento de Hunt, argumentar que nossa identidade historicamente mutante é formada pela experiência e a tradição narrativa da qual fazemos parte.

Ao levar nosso foco às traduções de literatura estrangeira, notamos como as obras traduzidas oferecem ao leitor uma janela ao mundo "do outro" e fazem com que, no caso específico de leitores infanto-juvenis, a partir de uma idade muito nova tenham contato e uma compreensão e aceitação de coisas "estrangeiras" ou fora da sua realidade cotidiana. 
Roland Barthes ressalta que "a cultura é, de certa maneira, o campo patológico por excelência, onde se inscreve a alienação do homem contemporâneo" (BARTHES: 2004, 112). Ele aponta que cada classe social não quer ser dona da cultura, sendo que a cultura está por toda parte. Questionamo-nos, junto a Barthes, como é que elas "olham para a linguagem do outro?"

Na América Latina e, particularmente, no Brasil a questão multicultural apresenta uma configuração própria. Nosso continente é um continente construído com uma base multicultural muito forte, onde as relações interétnicas têm sido uma constante através de toda sua história, uma história dolorosa e trágica principalmente no que diz respeito aos grupos indígenas e afrodescendentes. A formação histórica está marcada pela eliminação física do "outro" ou por sua escravização, que também é uma forma violenta de negação de sua alteridade. Os processos de negação do "outro" também se dão no plano das representações e no imaginário social (CANDAU: 2008, 17).

Ao buscar outras definições da palavra "multiculturalismo" para montar nosso mosaico de culturas e hábitos de leituras, e situarmos o tradutor literário e a própria tradução literária como mediadora sociocultural, recorremos às ideias de Vera Maria Candau (op. cit.). Ela aponta que existem três propostas para o multiculturalismo: 1) o multiculturalismo assimilacionista que procura integrar os grupos marginalizados e discriminados aos valores, mentalidades, conhecimentos socialmente valorizados pela cultura hegemônica, 2) o multiculturalismo diferencialista/plural que enfatiza o reconhecimento das diferenças, e 3) o multiculturalismo interativo/interculturalidade que promove uma educação para o reconhecimento do "outro" para o diálogo entre os diferentes grupos sociais e cultuais (CANDAU: 2010, 20-35).

A priori, a primeira proposta assimilacionista parece ser uma maneira justa e incorporadora para lidar como uma sociedade multicultural. A integração de grupos marginalizados para fazer parte de uma cultura hegemônica e supostamente feliz soa como um conto de fadas e como algo que realmente todos deveríamos desejar de uma sociedade. Ao adentrarmos um pouco mais à proposta, entretanto, torna-se visível que na atualidade não existe igualdade de oportunidades para todos/as.

Candau cita grupos como os indígenas, negros, homossexuais, pessoas de outros países, pessoas de classes sociais menos favorecidas e/ou com baixos níveis de escolarização, ou pessoas com deficiência, não têm o mesmo acesso a determinados 
serviços, bens e direitos fundamentais que outros grupos sociais têm. Em linhas gerais, esses outros grupos com direitos são de classe média ou alta, brancos, considerados "normais" e com elevados níveis de escolarização. Dentro da escola, para lidar com essas desigualdades, estratégias de caráter compensatório são implementadas. Em vez de valorizar as diferenças desses grupos diferentes, há uma deslegitimação de dialetos, saberes, línguas, crenças, valores 'diferentes' dos grupos que são de maneira explícita ou implicitamente inferior.

Ao passarmos para a segunda concepção de multiculturalismo diferencialista ou, em outras palavras, uma monocultura plural, encontramos a privilegização de formação de comunidades culturais homogêneas com suas próprias organizações - bairros, escolas, igrejas, clubes, associações, etc. Enquanto a valorização da cultura particular de cada grupo é desejável, corre o risco de tornar-se "verdadeiros apartheid socioculturais". Este fenômeno é presente em várias cidades dos Estados Unidos onde imigrantes mexicanos, brasileiros, indianos, chineses, africanos, entre outros acabam formando comunidades removidas do resto da sociedade "normal" norte-americana. Às vezes duas ou mais destas microculturas se formam numa mesma localidade, assim gerando um mosaico de culturas dentro da sociedade monofacetada; um exemplo perfeito do velho conceito de "separate but equal" 2 .

Dentro de uma perspectiva intercultural, Maria Candau promove uma hibridização cultural que é um elemento importante para se levar em consideração na dinâmica dos diferentes grupos socioculturais. É uma espécie de negociação cultural em que os diferentes grupos socioculturais recebem um tratamento mais justo através do reconhecimento das suas diferenças culturais. Obviamente a educação é uma ferramenta essencial para abrir o caminho a um reconhecimento cultural diferenciado. De acordo com Candau a interculturalidade é: "um processo dinâmico e permanente de relação, comunicação e aprendizagem entre culturas em condições de respeito, legitimidade mútua, simetria e igualdade...um espaço de negociação e de tradução" (2002, 23-24). É dentro do âmbito deste espaço de negociação que pretendemos embarcar numa breve caminhada pelo mundo da tradução literária.

\footnotetext{
${ }^{2}$ Separados mais iguais. Este termo se refere à doutrina legal dos Estados Unidos que justificava sistemas de segregação. No dia 17 de maio de 1954, foi determinado pela legislação Brown v. Conselho Nacional da Educação nos Estados Unidos que escolas públicas "separadas mais iguais" para alunos negros e brancos eram anticonstitucionais. Este movimento serviu para fortalecer o movimento para direitos civis no país. Para mais informação sobre a ação judicial Brown v. Board of Education, acesse o site: http://www.nationalcenter.org/brown.html - Tradução da autora.
} 


\section{Teorias Tradutológicas}

Os estudos da tradução ou a teoria da tradução é uma disciplina que, como aponta André Lefevere, junta trabalhos de uma grande variedade de campos tais como: linguística, estudos literários, história, antropologia e psicologia. Apesar do ato de traduzir ser algo com suas raízes na era romana e grega, a área de estudos da tradução tem atraído a atenção de muitos acadêmicos e tradutores profissionais ao longo dos últimos cinquenta anos. Da mesma maneira em que para cada crítico literário ou linguístico existe uma teoria literária ou linguística, dentro do campo de estudos da tradução existe uma pletora de teóricos e teorias sobre o ato de traduzir, a respeito do que constitui uma boa tradução, qual a influência de uma tradução na cultura em que é introduzida, técnicas de "domesticar ou estrangeirizar" uma tradução, etc.

O fato de que a área de estudos da tradução seja muito ampla com suas raízes no primeiro século da Era Cristã, com Cícero e Horácio, faz com que uma vista mais completa ou profunda de cada teórico e cada teoria tradutória de maior importância se torne algo impossível e nada prático para o escopo deste trabalho. Devido às restrições de tempo e ao fato de que o foco neste artigo é apresentar uma breve análise dos percalços enfrentados pelo tradutor ao traduzir uma obra literária do gênero infantojuvenil, propõe-se um breve resumo das principais teorias e métodos de tradução.

Até a segunda metade do século XX, a teoria da tradução debatia a técnica do tradutor em realizar uma tradução literal, livre ou fiel. A tradução literal baseava-se numa tradução "palavra por palavra" do texto original, assegurando assim a fidelidade ao texto original e aos propósitos literários do autor original. Em contrapartida, a tradução livre era uma versão "sentido por sentido" e seguia conceitos propostos por Cícero. De acordo com sua visão de realizar uma tradução fiel e livre, Cícero afirma que não encara a tradução como um intérprete, e sim como orador: "[...] keeping the same ideas and forms, or as one might say, the "figures" of thought, but in language which conforms to our usage. And in doing so, I did not hold it necessary to render word for word, but I preserved the general style and force of the language" (CÍCERO Apud MUNDAY, 2006). ${ }^{3}$

Cícero propagava uma tradução que capturasse o sentido do texto original, assim preservando o estilo, a força do texto original, ou seja, a alma e o espírito da mensagem

\footnotetext{
3 ...mantendo as mesmas ideias e formas; ou, como se poderia dizer, as "figuras" de pensamento, mas usando uma linguagem que está de acordo com a nossa. Ao fazer isso, eu não achei necessário render uma tradução palavra por palavra, mas bem preservei o estilo geral e a força da linguagem - Tradução da autora.
} 
original do autor. Horácio se aproximava deste conceito com sua ideia em Ars Poética quando falava de produzir um texto "prazeroso esteticamente e criativo" na sua tradução. São Jerônimo de Strídon, o mais famoso de todos os tradutores com suas traduções bíblicas do grego e hebraico ao latim, afirma sua técnica tradutória dizendo "eu faço uma tradução não palavra por palavra, mas sentido por sentido".

Em 1540 Etienne Dolet enumerou cinco princípios para traduzir bem de uma língua para outra língua. De acordo com Dolet, o tradutor deve entender perfeitamente o sentido e o texto do autor original, deve ter um conhecimento perfeito da língua de origem e da língua meta, deve evitar traduções palavra por palavra, deve evitar o uso de formas não muito comuns na tradução, e deve montar as palavras e frases eloquentemente para evitar uma tradução malfeita ou desajeitada (MUNDAY: 2006, 7- 26).

Passando para a Inglaterra do século XVII, Denham, Cowley e Dryden fizeram contribuições importantes à teoria tradutória. Em 1680 Dryden classifica o ato de traduzir em três categorias: metáfrase, paráfrase e imitação. A metáfrase se refere a uma tradução palavra por palavra e linha por linha da tradução, ou seja, uma tradução literal do texto. A paráfrase é uma tradução com latitude na qual o tradutor não perde a vista do autor original, mas muda frases para realizar uma tradução sentido por sentido. A última categoria se refere a uma adaptação do texto original, omitindo certas palavras e perdendo, às vezes, aspectos do sentido do texto de origem.

Depois de Dryden, outro inglês, Tytler, define seus princípios para uma "boa tradução". Para Tytler, existem três leis ou regras para render uma boa tradução: a tradução deveria expressar as ideias da obra original, o estilo e maneira de escrever deveriam ser do mesmo caráter do original, e a tradução deveria ter a facilidade da composição original. Em outras palavras, o tradutor deveria "adotar a própria alma do seu autor" (MUNDAY: 2006, 24-27).

O século XIX trouxe algumas mudanças em conceitos tradutórios influenciados em elementos do Romantismo. Em 1813, o teólogo e tradutor alemão Friedrich Schleiermacher distinguiu dois tipos distintos de tradutor: o Dolmetscher que traduzia apenas textos comerciais e o Übersetzer que trabalhava com textos acadêmicos e literários. Concebido como o pai da hermenêutica moderna, ele acreditava em dois caminhos para o verdadeiro tradutor: deixar em paz o escritor dentro do possível e levar o leitor até o 
escritor, ou deixar em paz o leitor dentro do possível e levar o escritor até o leitor. Ele propõe "alienar" e "naturalizar" textos para conseguir realizar seus propósitos tradutórios.

Estes dois conceitos tiveram uma grande influência em outro grande tradutor e acadêmico do século XX/XXI, Venuti com seus conceitos de "estrangeirização" (foreignization) e "domesticação" (domestication) de textos (MUNDAY: 2006, 27-34). Schleiermacher propagava a impossibilidade de um tradutor traduzir para uma língua que não fosse a língua materna. Ele ressaltava que: “... é um ato que corre tanto contra a natureza quanto a moralidade a se tornar um desertor a sua própria língua mãe e se render a outra" (SCHLEIERMACHER Apud LEFEVERE, 2003). Este conceito continua ainda hoje com grande parte dos tradutores profissionais do mundo trabalhando apenas de outra(s) língua(s) estrangeira(s) para a sua língua materna.

O teórico e linguista estruturalista russo-americano, Roman Jakobson, no seu artigo "On Linguistic Aspects of Translation" ("Sobre aspectos linguísticos da tradução") distingue três maneiras para interpretar um signo verbal: 1) através de uma tradução intralingual (rewording) que possibilita sua tradução em outro signo da mesma língua (rewording), 2) através da tradução interlingual (translation proper) interpretando os signos verbais por meio de outro idioma, e 3) tradução intersemiótica (transmutação) que interpreta os signos verbais por meio de sistemas de signos nãoverbais (JAKOBSON Apud VENUTI, 2004). Dentro dos seus estudos linguísticos e tradutórios, Jakobson aborda o problema de equivalência em sentido entre palavras de línguas diferentes. De acordo com sua teoria, a equivalência na diferença é o problema cardinal de linguagem e a preocupação crucial da linguística. A proposta de Jakobson, então, se concentra no problema de sentido, equivalência e diferenças de estrutura e terminologia de línguas em vez da inabilidade de uma língua transmitir uma mensagem que foi escrita em outra língua verbal. Ele destacava que as línguas diferem entre si essencialmente no que devem dizer e não no que podem dizer. Jakobson também considera a poesia como algo intraduzível que requer uma transposição criativa.

A questão de equivalência em sentido e intraduzibilidade de texto é retomada por Eugene Nida nos anos 1960s (MUNDAY: 2006, 36-38). Em seu artigo "Theories of Translation" (Teorias da Tradução), o tradutor, especialista em traduções bíblicas, Eugene A. Nida, destaca quatro principais perspectivas no tema de comunicação interlingual. Ao longo da história, a perspectiva filológica tem focalizado na fidelidade do texto traduzido. Esta perspectiva, como aponta Nida, foi de suma importância no caso das 
traduções bíblicas, citando as contribuições importantíssimas de Luther, Cowley, Dryden e Pope deste âmbito, e mais recentemente do George Steiner.

A segunda perspectiva aventada por Nida é a linguística com base nos estudos linguísticos de teóricos como Jakobson e Chomsky. Outros estudos que entram dentro desta perspectiva são estudos de elementos linguísticos e culturais em comunicação e a maneira como são processados pelo cérebro. Nida destaca outro estudioso neste campo, Lambert, com seus estudos sobre bilinguismo que contribuem para a compreensão na maneira em que tradutores e intérpretes processam e trabalham com a linguagem nos seus trabalhos.

A terceira perspectiva é a comunicativa que reflete a importância de um número de elementos básicos na teoria da comunicação, tais como língua de origem (source textST), mensagem, receptor e médium. Trabalha também com os processos de codificação e descodificação de mensagens na comunicação original e como estes se comparam com os outros mais complexos do processo de tradução. Dentro desta perspectiva que dá ênfase nas estruturas de discurso para validar a tradução de acordo com a capacidade do texto original e do receptor em cumprir com suas funções, destacam-se contribuições de Susanne Langer, Jakobson, Grimes, Traugott e Pratt.

A quarta e última perspectiva relatada por Nida é a sócio-semiótica. Nesta perspectiva, o foco principal são os múltiplos códigos envolvidos em qualquer ato de comunicação verbal. Nida ressalta que as vantagens do uso da perspectiva sóciosemiótica são múltiplas, e cita o uso de epistemologia realista para falar sobre a vida real de experiências cotidianas, sendo fundamentada na relação triádica entre signo, referente e intérprete como uma delas. No seu artigo, "Principles of Correspondence"

(“Os Princípios da Correspondência”), ele comenta duas orientações básicas na tradução: formal e dinâmica. Ele afirma que não existem equivalências idênticas, e que é necessário procurar a equivalência mais próxima em uma tradução.

Nida fala de distanciamento linguístico e cultural e o papel do tradutor em fazer uso de mudanças formais na tradução. Um dos críticos mais veementes de Nida é o acadêmico Edwin Gentzler. A partir de uma perspectiva desconstrucionista, na sua obra Contemporary Translation Theory (Teoria Contemporânea da Tradução), ele denega o trabalho de Nida por seu ponto de vista teológico com o conceito de que equivalência dinâmica serve para converter os receptores, independente da sua cultura, ao discurso dominante e as ideias do cristianismo protestante. 
Nos anos 1960 Catford publica sua obra A Linguistic Theory of Translation (Uma Teoria Linguística da Tradução) e oferece uma contribuição imprescindível da mudança (shift) envolvida na tradução. Ele define shift como saídas da correspondência formal no processo de transferência da língua de origem à língua meta. Os shifts seriam em nível (algo que se representa lexicamente em uma língua e lexicalmente em outra) ou em categoria (estrutura, classe, unidade ou intra-sistema) (MUNDAY: 2006, 60-62). No seu artigo "Possibilidade(s) de Tradução(ões)", Mauri Furlan destaca as contribuições do Catford à teoria linguística da tradução uma teoria “...na qual se consideram as relações da língua como atividade intralinguística, com níveis e categorias formais da linguística geral, e como atividade extralinguística, com seus meios de expressão e as situações, sempre únicas, quando da produção linguísticas” (FURLAN: 1998, 17).

André Alphons Lefevere, um dos teóricos de tradução mais influentes da última metade do século $\mathrm{XX}$, apresenta a tradução como uma reescrita de um texto original. Todas estas obras reescritas refletem uma ideologia específica que tem a capacidade de manipular a literatura para funcionar dentro de uma sociedade numa maneira particular e específica. Ao pensar especificamente sobre a influência da cultura no processo de tradução, Lefevere aponta a tradução de literatura como tendo lugar:

[...] not in a vacuum in which two languages meet, but, rather, in the context of all the traditions of the two literatures [...] Translators are the artisans of compromise [...] Since they are at home in two cultures and two literatures, they also have the power to construct the image of one literature for consumption by the readers of another. (LEFEVERE: 1992, 6)

Junto a Susan Bassnett (2002), Lefevere (2003) afirma que não é a palavra nem o texto que é a unidade operacional da tradução. O que realmente "se traduz" numa tradução de um texto e o que se constitui como a menor unidade de tradução é a própria cultura do país. Outro grande teórico da área da teoria da tradução, Edwin Gentzler (1990), aponta que este conceito de tradução cultural é realmente um verdadeiro passo histórico para o campo de estudos da tradução. Ele afirma que simboliza "o advento da era da disciplina de estudos da tradução" no sentido que potencializa um aumento intercultural ou multicultural entre os países do mundo.

\footnotetext{
${ }^{4}$ [...] não dentro de um vácuo em que duas línguas se encontram, mas bem dentro do contexto de todas as tradições das duas literaturas [...] Os tradutores são as artesãs de negociação [...] Sendo que eles se sentem em casa em duas culturas e duas literaturas, eles também têm o poder de construir a imagem de uma literatura para o consumo dos leitores de outra (cultura). Tradução da autora.
} 
Uma questão importante ao estudo da tradução é a receptividade do leitor ao texto traduzido. Nenhum escritor ou tradutor pode ter certeza que o leitor final vai realmente compreender a mensagem ou código do texto original ou traduzido. O leitor sempre acaba trazendo traços de sua própria personalidade e experiências ao ato de ler, interpretar e compreender um texto. O conceito bakhtiano de dialogismo apresenta que tudo na vida pode ser compreendido como parte de algo maior no sentido que existe uma constante interação entre significados.

A tradutora finlandesa, Oittinen, fala como toda palavra nasce dentro de um diálogo. Nesta situação, uma palavra, um idioma, uma cultura são dialogados ou relativizados com outra palavra, outra discussão, outro idioma, outra cultura (Oittinen: 2000, 30). Ela aponta que traduções, diferentes dos seus originais, sempre combinam o velho com o novo. Para render uma tradução perfeita, o tradutor precisa " [...] make the partly alien words into words of her/his own; the Word in a translation necessarily contains the translator's intentions and feelings, too" (OITTINEN: 2000, 31). ${ }^{5}$ Um livro que é traduzido em outro idioma acaba ganhando uma nova vida, novos sentidos e uma nova visão dentro da nova cultura a partir das novas leituras dos leitores estrangeiros. Sendo assim, podemos afirmar que uma tradução nunca pode ser igual ao original. Sempre existirá uma divergência do texto original devido a diferentes leituras, diferenças de cultura, divergências de época, entre outros fatores sociolinguísticos.

$\mathrm{Na}$ introdução à filosofia da tradução do teórico francês Paul Ricoeur no livro On Translation (Sobre a Tradução), Richard Kearney aponta que existem dois paradigmas de tradução para Ricoeur. Em primeiro lugar existe um paradigma linguístico que se refere a como as palavras se relacionam com os sentidos dentro de uma língua ou entre línguas. Segundamente, existe o paradigma ontológico que se refere à maneira em que ocorre a tradução entre um ser humano e outro. Kearney fala da multiplicidade de idiomas, mas de uma singularidade de linguagem. É nisso que se fundamenta a necessidade primordial para a tradução. Ele ainda aponta que o ligamento ou elo comum entre todos os idiomas é a capacidade de mediar um ser falante e um mundo de significados (atuais e possíveis).

Ricoeur fala da necessidade de uma hospitalidade linguística para conseguir render uma boa tradução. Esta hospitalidade linguística seria o ato de habitar a palavra

\footnotetext{
${ }^{5}[\ldots]$ fazer com que as palavras parcialmente estrangeiras se tornem suas próprias palavras; a palavra em uma tradução necessariamente contém as intenções e sentimentos do tradutor também. Tradução da autora.
} 
"do outro" enquanto receber a palavra "do outro" na sua própria casa, seu lugar de morar (RICOEUR: 2006, xvi). Toda tradução envolve um diálogo entre o tradutor e o estrangeiro. Neste diálogo o tradutor precisa aceitar as diferenças para conseguir interpretar os códigos linguísticos e culturais e transformá-los em uma linguagem inteligível no seu próprio lugar, sua cultura.

Ricoeur acreditava que a melhor maneira de se conhecer é através do conhecimento "do outro". Ele até propõe que o futuro da política mundial deveria se basear numa troca de memórias e narrativas entre diferentes nações, porque só traduzindo nossas feridas na linguagem dos outros "estrangeiros" e re-traduzir as feridas deles na nossa própria linguagem poderia funcionar como o começo de um processo de melhoramento e reconciliação (RICOEUR: 2006, xx). A partir desta afirmação percebemos o poder da palavra e, mais que isso, da palavra traduzida.

Ricoeur nos traz o conceito da intraduzibilidade do texto estrangeiro e também da tradução ou texto traduzido como um terço texto não-existente. Para render uma boa tradução, o primeiro idioma “origem” tem que se ligar perfeitamente com o segundo idioma "chegada". É o terceiro texto inexistente que faz a ligação intertextual para assegurar a transferência idêntica de mensagem (linguagem, cultura, entre outros elementos).

Ricoeur faz uso da teoria de Freud de "memória" e "luto" para desistir e aceitar a impossibilidade da tradução perfeita. O luto a que se refere é o reconhecimento e aceitação do tradutor em não poder servir dois mestres: o autor e o leitor. O luto seria para aquele aspecto minucioso que se perde na impossibilidade de traduzir um texto ao outro. $\mathrm{O}$ filósofo afirma que o luto para a tradução perfeita produz a felicidade que provem do ato de traduzir. Ele aponta que no caso da tradução são os textos e os grupos culturais que na verdade são de importância. O tradutor precisa entender o "estrangeiro" com seus costumes e idiomas diferentes.

No seu livro, Ricoeur faz referência à obra de grande importância linguística de Walter Benjamin, The Translator's Task (A Tarefa do Tradutor). Na sua obra, Benjamin apresenta o ato de tradução como um modo e para entendê-lo é necessário voltar ao texto original. Ele afirma que uma tradução, não importa a qualidade da mesma, não pode significar nada para o texto original. Uma tradução procede do original, mas na tradução 
o original aumenta em tamanho linguístico a atingir um grau mais elevado e puro de reconhecimento e apreciação.

O que nunca pode ser traduzido e o que Benjamin chama intraduzível é o "poético". A poesia é algo intraduzível devido à incompreensibilidade do segredo poético que é a alma da poesia. Para colocarmos este conceito em uma situação real, traduzir um manual de maquinaria não requer uma compreensão do segredo poético. Requer um treinamento específico dentro da área de tradução e, às vezes, dentro da área de maquinaria. Um manual não contém uma alma poética. Para Benjamin, a tarefa do tradutor consiste em encontrar a intenção a respeito do idioma no qual a obra será traduzida, para despertar uma reverberação da obra original: um eco da obra original.

Ao adentrarmos a teoria dos polissistemas e o polissistema literário, tomaremos como base os conceitos e princípios da tradução de literatura infanto-juvenil propostas pelos teóricos israelenses Gideon Toury e Itamar Even-Zohar. No início dos anos 1970, surgiu um grupo de pesquisa cujo foco principal foi a tradução literária. $\mathrm{O}$ fruto deste grupo foi uma área chamada Estudos Descritivos da Tradução (Descriptive Translation Studies - DTS). A base deste grupo foi o Formalismo russo e o Estruturalismo Tcheco, mas a teoria que surgiu do trabalho destes pesquisadores foi dos polissistemas; ou seja, o estudo da tradução de literatura dentro de uma perspectiva mais ampla de sistemas como cultura, política, arte, religião, entre outros. Even-Zohar define polissistema como um sistema múltiplo: “[...] a system of various systems which intersect with each other and partly over-lap, using concurrently different options, yet functioning as one structured whole, whose members are interdependent (EVEN-ZOHAR: 1990, 11). ${ }^{6}$

Shavit propõe uma tradução que seja o resultado do relacionamento entre o sistema de origem (source system) e sistema de meta (target system). Colocando o tradutor no papel de uma espécie de mediador, Shavit afirma que existem dois princípios que o tradutor deveria seguir ao traduzir literatura infantil, deixar o texto de acordo com o que a sociedade acredita (em certo momento), ser educacionalmente

"bom para a criança" e ajustar o enredo, caracterização e linguagem para as percepções prevalentes da habilidade da criança em ler e compreender (SHAVIT: 1986, 111-113). Apesar de adotar a visão sistêmica de Even-Zohar, Toury desenvolveu uma metodologia

\footnotetext{
${ }^{6}[\ldots]$ um sistema de vários sistemas que se cruzam uns com os outros e se sobrepõem parcialmente, através do uso de opções concorrentemente diferentes, mas que funcionam como um todo estruturado, cujos membros são interdependentes. Tradução da autora.
} 
própria para estudos da tradução baseada em "norma". Segundo ele, as normas se estendem para além dos limites textuais da literatura:

Translation activities should rather be regarded as having cultural significance. Consequently, translatorship amounts first and foremost to being able to play a social role, i.e., to fulfill a function allotted by a community [...] The acquisition of a set of norms for determining the suitability of that kind of behavior, [...] is therefore a prerequisite for becoming a translator within a cultural environment (TOURY: 1995, 53). ${ }^{7}$

Para Toury, a tradução preenche uma necessidade ou vazio dentro da cultura-alvo.

Sendo assim, a necessidade e o modo de traduzir se torna algo "target oriented"; ou seja, direcionada à cultura-alvo.

Professor da Temple University e tradutor Lawrence Venuti pode ser considerado um dos estudiosos de estúdios tradutórios na última década devido a suas contribuições sobre a estrangeirização (foreignizing) do texto meta (TT). Sua tese é que a tradução está se tornando uma prática invisível dentro dos Estados Unidos. A técnica tradutória de domesticação apaga as diferenças culturais e linguísticas do texto estrangeiro ao convertêlo num texto que conseguirá a aceitação da cultura meta. Domesticação compreende-se nas estratégias que levam ao apagamento, na tradução dos elementos estrangeiros presentes em um texto, sendo a estrangeirização o oposto.

Em seu artigo "Towards a Translation Culture" (Rumo a uma Cultura de Tradução), Venuti aborda as dificuldades de uma verdadeira cultura da tradução. Ele propõe a necessidade de uma cultura na qual textos traduzidos são escritos e lidos, ensinados e estudados, reconhecidos como obras que não simplesmente são distintas dos textos de origem que eles traduzem, mas que são vitais à cultura de destino que está recebendo a tradução e aos intercâmbios constantes e eternos com outras culturas estrangeiras. Venuti define a tradução como um processo pelo qual uma cadeia de significantes que constitui o texto da língua de origem é trocada por uma cadeia de significantes na língua de chegada, que o tradutor propõe no poder de uma interpretação (VENUTI: 2004, 17). Ele cita Edith Grossman e sua descrição do conceito instrumental do trabalho do tradutor. Segundo Grossman, a descrição mais fundamental de que se faz o tradutor:

\footnotetext{
${ }^{7}$ As atividades de tradução deviam ser consideradas como tendo significado cultural. Consequentemente, ser tradutor culmina principalmente na capacidade de exercer um papel social, ou seja, cumprir uma função que lhe foi concedida por uma comunidade. [...] A aquisição de um conjunto de normas para a determinação da adequação deste tipo de comportamento, [...] é, portanto, um pré-requisito para se tornar tradutor dentro do ambiente cultural. Tradução da autora.
} 
Is that we write - or perhaps rewrite - in language B a work of literature originally composed in language A, hoping that readers of the second language - I mean, of course, readers of the translation - will perceive the text, emotionally and artistically, in a manner that parallels and corresponds to the esthetic experience of its first readers (GROSSMAN Apud VENUTI, 2004). ${ }^{8}$

Venuti questiona quais "first readers" (primeiros leitores) seriam esses mencionados por Grossman. Ela cita a dificuldade para um tradutor de estar seguro de que uma tradução realize as intenções originais do autor quando aquele autor não tinha a intenção de escrever na língua de destino. Grossman afirma que essencialmente o tradutor pode apenas aspirar ou ter a esperança de produzir um efeito equivalente na sua tradução do sentido original do texto de origem.

Diferente do método instrumental discutido por Grossman, Venuti oferece uma abordagem hermenêutica da tradução do texto de origem. Ele aponta que uma tradução nunca consegue se comunicar livremente e sem problemas devido ao fato do tradutor negociar as diferenças linguísticas e culturais do texto estrangeiro ao reduzi-las e oferecer outras referências, basicamente domésticas, tiradas da língua receptora para tornar-se possível a recepção do estrangeiro. Sendo assim, o texto estrangeiro não é comunicado propriamente dito, e sim inscrito com inteligibilidades e interesses domésticos. É sempre reconstruído de acordo com valores diferentes e sempre variável de acordo com línguas e culturas diferentes.

Venuti ressalta que: "Translators should be able to give an account of their work that is cognizant of these cultural conditions. They should be able to show how, given these conditions, their translation aims to fix the form and meaning of the source text so as to inscribe a particular interpretation" (VENUTI: 2004, 17). ${ }^{9}$

Venuti, ao se referir à interpretação do texto meta pelo tradutor, afirma que o tradutor o altera de forma significativa. O texto se encontra deslocado de seu contexto original onde apoiava sentidos, valores, e funções específicas à língua e cultura de origem, e é inserido simultaneamente num contexto diferente, criado pela tradução, onde apoia sentidos, valores e funções específicas à língua e cultura receptora. Este ponto é mais que uma obra literária é muito mais que qualquer tipo de correspondência: é um artefato

\footnotetext{
${ }^{8}$ É que escrevemos - ou talvez re-escrevamos - na língua B uma obra literária originalmente escrita na língua $\mathrm{A}$, na esperança de que os leitores da segunda língua - quero dizer, obviamente, os leitores da tradução - tenham a mesma percepção, emocionalmente e artisticamente, numa maneira paralela que corresponde à experiência estética dos seus primeiros leitores. - Tradução da autora.

${ }^{9}$ Os tradutores deveriam conseguir dar um relato de seu trabalho que é ciente de estas condições culturais. Eles deveriam conseguir mostrar como, dadas estas condições, sua tradução visa fixar a forma e o sentido do texto de origem para inscrever uma interpretação específica. - Tradução da autora.
} 
cultural complexo que nunca sobrevive intato a mudança a outra língua e cultura aonde chega a significar, a ser valorizado, e a funcionar diferentemente (VENUTI: 2004, 17). Sendo assim, de acordo com Venuti, se os tradutores querem mudar a marginalidade cultural da tradução, eles precisam mudar a maneira em que eles mesmos pensam sobre e representam seus trabalhos (VENUTI: 2004, 17).

Em artigo de sua autoria, Translation, Community, Utopia (Tradução, Comunidade, Utopia), Venuti menciona como uma tradução, principalmente de um texto literário, envolve uma liberação de uma sobra doméstica. Ele afirma: "The foreign text is rewritten in domestic dialects and discourses, registers and styles, and this results in the production of textual effects that signify only in the history of the domestic language and culture" (VENUTI: 2004, 471). ${ }^{10}$ Venuti usa o termo "invisibilidade" do tradutor no seu livro The Translator's Invisibility (A Invisibilidade do Tradutor) para descrever a situação do tradutor e a atividade dentro da cultura contemporânea AngloAmericana. Na visão de Venuti, o tradutor é um agente poderoso para a mudança cultural. Ele cita Norman Shapiro ao dizer que ele vê a tradução como: "A good translation is like a pane of glass. You only notice it's there when there are little imperfections - scratches, bubbles. Ideally, there shouldn't be any. It should ever call attention of itself" (SHAPIRO Apud VENUTI, 2004). ${ }^{11}$

O poeta e tradutor mexicano, Octavio Paz, fala da tradução como uma transferência de um termo desconhecido em palavras simples que já sabe dentro da sua língua. Ele usa o exemplo de uma criança que pergunta a sua mãe sobre o sentido de uma palavra. O que a criança realmente busca é a tradução da palavra em outras palavras mais simples que já conhece. Paz destaca a pluralidade de línguas e sociedades no mundo moderno. Cada língua é uma vista do mundo, e cada civilização um mundo.

No seu livro, Translation Studies (Estudos Tradutórios), Susan Bassnett cita Octavio Paz e seu conceito de que todos os textos, sendo parte de um sistema literário que descende de e se relaciona com outros sistemas:

Every text is unique and, at the same time, it is the translation of another text. No text is entirely original because language itself, in its essence, is already a translation: firstly, of the non-verbal world and secondly, since every sign and

\footnotetext{
${ }^{10} \mathrm{O}$ texto estrangeiro é reescrito em dialetos e discursos, registros e estilos domésticos, e isto resulta na produção de efeitos textuais que tem significância apenas dentro da historia da língua e cultura doméstica. - Tradução da autora.

${ }^{11}$ A boa tradução parece-se com uma vidraça de janela, você só percebe que está aí quando existem pequenas imperfeições - arranhões, bolhas. Idealmente, não deveria ter nenhuma. Nunca deveria chamar a atenção a si mesmo. - Tradução da autora.
} 
every phrase is the translation of another sign and another phrase. However, this argument can be turned around without losing any of its validity: all texts are original because every translation is distinctive. Every translation, up to a certain point, is an invention and as such it constitutes a unique text (PAZ Apud BASSNETT, 2002, p. 46). ${ }^{12}$

Sendo assim, percebemos a lógica da afirmação de Paz de que todos os textos são em atualidade "traduções de traduções de traduções".

\section{Conclusão}

$\mathrm{Na}$ linha do tempo das teorias tradutológicas apresentadas, de forma reduzida, neste artigo, averiguamos como, lembrando o pensamento de Walter Benjamin, a tarefa do tradutor é muito mais de que apenas dar significado às palavras originais em outra língua. É, portanto, uma reverberação ou eco da obra original, mas com suas próprias características e alma poética. A tradução literária tem, recorrendo às teorias de Toury e Even-Zohar, um lugar ainda mais importante dentro da cultura ou sistema sociocultural de um povo. Sendo assim, o tradutor ocupa o papel de uma espécie de mediador de culturas e a tradução literária contem significância sociocultural preenchendo, segundo Toury, uma necessidade ou vazio dentro da cultura-alvo.

Com base nos conceitos e métodos de tradução de teóricos tais como Edwin Gentzler, Lawrence Venuti, Eugene Nida, André Lefevere, Paul Ricoeur e Zohar Shavit, entre outros, analisamos os aspectos socioculturais de uma tradução literária, assim como oferecemos uma breve abordagem dos métodos e dos desafios da tradução de textos literários. Presenciamos como a tradução literária e o tradutor literário desempenham papeis de mediadores socioculturais imbuídos com o poder de ultrapassar tempos, culturas e histórias para trazer novas experiências, perspectivas e prazeres para uma multiplicidade de leitores em culturas e países diferentes. Averiguamos como o tradutor literário é uma espécie de guardião de segredos que leva e traz informação na procura incessante de significado cultural e literal entre o texto e cultura de partida (TP \& CP) e o texto e cultura de chegada (TC \& CC). O resultado é um lindo objeto de arte, não precisamente o texto

\footnotetext{
${ }^{12}$ Todo texto é único e, ao mesmo tempo, a tradução de outro texto. Nenhum texto é integralmente original, porque a linguagem em si, em sua essência, já é uma tradução: primeiramente, do mundo nãoverbal e segundamente, sendo que todo signo e toda frase é a tradução de outro signo e de outra frase. Entretanto, este argumento pode ser revertido sem perder sua validade: todos os textos são originais porque cada tradução é distinta. Toda tradução é, até certo ponto, uma invenção e como tal constitui um texto único. Tradução da autora.
} 
original em outra língua, mas uma reverberação que lembra o original, mas ao mesmo tempo se mostrando algo culturalmente e linguisticamente novo e inovador.

\section{Referências}

BAKHTIN, M. A estética da criação verbal. Tradução M. E. Galvão e G. Pereira. São Paulo, SP: Martins Fontes, 2000.

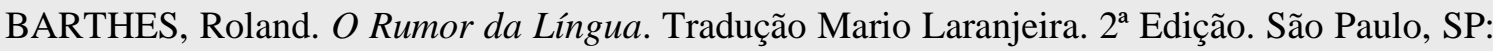
Martins Fontes, 2004.

BASSNETT, Susan. Translation Studies. London: Routledge, 2002.

BENJAMIN, Walter. The Translator's Task. Tradução Steven Rendall. TTR: Traduction, Terminologie, Redaction, Vol. 10, № 2, 1997, P. 151-165.

CANDAU, Vera Maria e MOREIRA, Antonio Flávio. Multiculturalismo: Diferenças Culturais e Práticas Pedagógicas. $4^{\mathrm{a}}$ Edição. Petrópolis, RJ: Vozes, 2010.

DERRIDA, Jacques. What is a "Relevant" Translation. Tradução Lawrence Venuti. Critical Inquiry, Vol. 27, No. 2 (Winter, 2001). The University of Chicago Press. P. $174-200$.

EVAN-ZOHAR, Itamar. Polysystem Studies: Poetics Today. Tel Aviv, v. 11, n. 1. Nov. 1990, P. 9- 78 .

FURLAN, Mauri. Possibilidade(s) de Tradução(ões). IN Cadernos de Tradução, $\mathrm{N}^{\mathrm{o}} 111$. Florianópolis, UFSC, 1998 (p. 89-111).

GENTZER, Edwin. Contemporary Translation Theory. Vanderbilt University, 1990.

."Translation, Postcolonial Studies, and the Americas". In: Paula Burnett (ed.), Translation and Transcreation, Vol. 2, No. 2. Brunel University: EnterText, 2003.

HALL, Stuart. Identidade Cultural na Pós-Modernidade. Tradução Tomaz Tadeu da Silva e Guaracira Lopes Louro. 11. ed. Rio de Janeiro: DP\&A, 2006.

HUNT, Peter. Understanding Children's Literature. New York, NY: Routledge, 1999.

JAKOBSON, Roman. Linguística e Comunicação. 22ª Edição. Tradução Izidoro Blikstein e José Paulo Paes. São Paulo, SP: Cultrix, 1999.

LEFEVERE, ANDRÉ. Translation, History, Culture: A Sourcebook. Taylor \& Francis ELibrary Edition, 2003.

. Translating literature: Practice and theory in a comparative literature context. New

York: MLA, 1992.

MUNDAY, Jeremy. Introducing Translation Studies: Theories and Applications. Oxon, England: Routledge, 2001.

NIDA, Eugene A. Theories of Translation. TTR: Traduction, terminologie, redaction, Vol. 4, No. 1, 1991, p. 19-32. 
1969.

The Theory and Practice of Translation. Leiden, The Netherlands: United Bible Societies,

OITTINEN, Riitta. Translating for Children. Taylor \& Francis e-Library Edição, 2002.

PAZ, Octavio. Translation: Literature and Letters. Tradução de Irene del Corral de Traducción: Literature y Literalidad. Barcelona, Espanha: Tusquets, 1971.

RICOEUR, Paul. On Translation. Tradução Eileen Brennan. Oxon, England: Routledge, 2006.

VENUTI, Lawrence. The Translation Studies Reader. London: Routledge, 2004. . The Translator's Invisibility: A History of Translation. Taylor \& Francis e-Library, 2004.

Towards a Translation Culture. In: The Iowa Review Forum on Literature and Translation. Temple University. www.iowareview.org.

Recebido em 15 de setembro de 2014 Aceito para a publicação em 20 de dezembro de 2014 